\title{
Perfil peptídico de hidrolisados enzimáticos de leite em pó desnatado
}

\author{
Rosângelis Del Lama Soares ${ }^{1}$, Viviane Dias Medeiros Silva ${ }^{1}$, Daniella Cristine Fialho Lopes ${ }^{1}$, Roberto \\ Gonçalves Junqueira ${ }^{1}$, Amintas Fabiano de Souza Figueiredo ${ }^{2}$, Marialice Pinto Coelho Silvestre ${ }^{1 *}$ \\ ${ }^{1}$ Departamento de Alimentos, Faculdade de Farmácia, Universidade Federal de Minas Gerais, ${ }^{2}$ Departamento de \\ Análises Clínicas e Toxicológicas, Faculdade de Farmácia, Universidade Federal de Minas Gerais
}

*Correspondência:

M. P. C. Silvestre

Departamento de Alimentos

Faculdade de Farmácia

Universidade Federal de Minas Gerais

Av. Antônio Carlos, 6627

31270-901 - Belo Horizonte - MG

E-mail:malice@farmacia.ufmg.br
Sete hidrolisados de leite em pó desnatado foram preparados, visando à produção de hidrolisados protéicos, como suplemento dietético para fenilcetonúricos. Para isso, utilizaram-se uma protease do Aspergillus oryzae (AO), a papaina (PA) e a pepsina (PE), isoladamente ou em associação, em diferentes relações enzima:substrato (E:S), sendo o tempo total de reação de 5 h e a temperatura de $50{ }^{\circ} \mathrm{C}$. Adotou-se como critério para a avaliação nutricional dos hidrolisados, o estudo da distribuição dos peptídeos nas amostras, de acordo com o tamanho da cadeia. Inicialmente, os hidrolisados foram fracionados por cromatografia líqüida de alta eficiência de exclusão molecular (SE-HPLC) e, para a quantificação dos componentes das frações cromatográficas, empregou-se o método rápido da Área Corrigida da Fração (ACF). Os resultados indicaram que, de modo geral, a ação isolada das três enzimas foi mais vantajosa em relação ao perfil peptídico em comparação com as associações estudadas. Entre todas as preparações testadas, a ação isolada de AO e de PA, e a associação destas enzimas (relação E:S de $1 \%$ e 2\%, respectivamente) produziram hidrolisados com perfis peptídicos semelhantes, mais adequados nutricionalmente, ou seja, com maior teor de di-e tripeptídeos e menor proporção de aminoácidos livres.
Unitermos:

- Suplemento dietético

- Perfil peptídico

- Hidrólise enzimática

- Fenilcetonúria

- Leite em pó desnatado

\section{INTRODUÇÃO}

Desde 1940, os hidrolisados enzimáticos de proteínas vêm sendo utilizados com finalidades terapêuticas para a recuperação ou a manutenção do estado nutricional de pacientes com restrições protéicas ou de aminoácidos em sua dieta. Desta forma, estas preparações enzimáticas têm sido utilizadas, tanto como suplemento em dietas para idosos e desportistas, como na fabricação de alimentos especiais para recém-nasci- dos prematuros, crianças com diarréia, gastroenterites, síndromes de má-absorção, fenilcetonúria (PKU) e outros erros inatos do metabolismo (Takase et al., 1979; Smithers, Bradford, 1991; Freitas et al., 1993; Frokjaer, 1994; Mahan, Stump, 1998; Clemente, 2000; Mira, Marquez, 2000). Ressalta-se, ainda, o crescente interesse tecnológico pelos hidrolisados enzimáticos protéicos, uma vez que a hidrólise enzimática pode contribuir para a melhoria das propriedades funcionais das proteínas (Cândido, 1998; Leónil et al., 2000). 
Há, na literatura, vários trabalhos comparando a absorção de aminoácidos resultantes da hidrólise enzimática de proteínas, com misturas equivalentes de aminoácidos livres. Constatou-se que a velocidade de absorção intestinal de aminoácidos é, consideravelmente, maior para as soluções contendo di- e tripeptídeos ou proteínas parcialmente hidrolisadas do que para as soluções contendo apenas aminoácidos livres (Adibi, Morse, 1971; Adibi, Soleimanpour, 1974; Hara et al., 1984; Keohane et al.,1985; Grimble et al., 1989).

O valor nutricional dos hidrolisados depende da qualidade da proteína utilizada, a qual deverá ser de alto valor biológico, do método de hidrólise e dos tamanhos das cadeias peptídicas nos hidrolisados (Grimble et al., 1989; Silvestre et al., 1994a,b). Segundo Gonzáles-Tello et al . (1994), a avaliação da qualidade nutricional dos hidrolisados protéicos deve envolver a análise dos seus perfis peptídicos. Os hidrolisados de melhor qualidade devem apresentar elevados teores de di- e tripeptídeos, assim como de peptídeos com massa molecular média de $500 \mathrm{Da}$. Além disso, devem conter baixos teores de aminoácidos livres e de peptídeos com massa molecular superior a $800 \mathrm{Da}$.

Duas patentes foram encontradas na literatura, relativas à preparação industrial de hidrolisados protéicos de caseína com elevado teor de di- e tripeptídeos. Na primeira, Chataud et al. (1988) testaram várias condições hidrolíticas, utilizando duas enzimas bacterianas e a tripsina, isoladas ou em associação. Na segunda, Loosen et al. (1991) prepararam diferentes hidrolisados protéicos, utilizando três enzimas bacterianas. Entretanto, os autores não mencionaram se as enzimas foram empregadas separadas ou em associação. Nos dois trabalhos, os peptídeos com massas moleculares superiores a 10.000 ou $15.000 \mathrm{Da}$ foram separados por ultrafiltração. $\mathrm{O}$ fracionamento dos hidrolisados foi realizado por HPLC capilar e de troca de ligante (LE-HPLC), porém não relataram o método escolhido para a quantificação dos peptídeos. Segundo os autores destes dois trabalhos, foram obtidos elevados teores de di- e tripeptídeos, além de baixos teores de aminoácidos livres. Entretanto, os métodos de fracionamento utilizados são considerados ineficazes para separar os di-e tripeptídeos dos peptídeos com maior número de resíduos de aminoácidos (Lemieux, Amiot, 1989; Davis, Lee, 1992).

Alguns autores têm utilizado várias enzimas, em diferentes condições hidrolíticas para a obtenção de hidrolisados protéicos com baixos teores de fenilalanina (Kitagawa et al., 1987; Lopez-Bajonero et al., 1991; Moszczynski, Idziak, 1993; Kasai et al., 1994; Outinen et al., 1996; Shimamura et al., 1999). Entretanto, em nenhum dos trabalhos descritos na literatura, relacionados à prepa- ração de formulações para fenilcetonúricos, foi realizada avaliação do perfil peptídico dos hidrolisados. Sendo assim, torna-se importante a utilização de métodos eficientes tanto para o fracionamento quanto para a quantificação de peptídeos e de aminoácidos livres dos hidrolisados protéicos em estudo, como o descrito por Silvestre et al. (1994b).

Neste trabalho, foram utilizadas três enzimas para o preparo de hidrolisados de leite em pó desnatado: a papaína, a pepsina e uma protease do Aspergillus Oryzae. A papaína, uma sulfidrilo protease, apresenta baixa especificidade, hidrolisando ligações amida e éster, tanto em peptídeos como em proteínas (Liener, 1974; Reed, 1975). A pepsina é uma protease do ácido gástrico e tem ampla especificidade para ligações peptídicas contendo aminoácidos aromáticos adjacentes. A protease tipo XXIII do Aspergillus oryzae possui baixa especificidade (Loosen et al., 1991).

No Brasil, as formulações dietéticas essenciais ao tratamento de fenilcetonúricos são geralmente importadas, de alto custo e constituídas basicamente de aminoácidos livres (NUPAD, 2002).

Este trabalho teve por objetivo o estudo dos efeitos das ações de três enzimas, a papaína, a pepsina e uma protease do Aspergillus oryzae, isoladas ou em associação, sobre o perfil peptídico de hidrolisados de leite em pó desnatado, visando à preparação, no futuro, de um produto dietético de alto valor nutricional, para ser utilizado por fenilcetonúricos.

\section{MATERIAL E MÉTODOS}

\section{Material}

O sistema de cromatografia líqüida de alta eficiência (HPLC) usado no fracionamento dos hidrolisados protéicos consistiu de uma coluna cromatográfica PHEA [poli-(2-hidroxietilaspartamida)-sílica], $250 \times 9,4 \mathrm{~mm}, 5 \mu \mathrm{m}$ e $200 \AA$ (PolylC, Columbia, MD, EUA), uma bomba isocrática e um detector espectrofotométrico em UV-VIS (série HP1100, Waldbronn, Alemanha), acoplado a um computador com software HPchemstation (Avondale, EUA). As amostras foram liofilizadas no liofilizador Free Zone, modelo 77500, Labconco (Kansas City, MI, EUA). A pancreatina (25 USP unid. de atividade de amilase, 2,0 USP unid. de atividade de lipase e 25 USP unid. de atividade de protease $/ \mathrm{mg}$ de sólido), a tripsina (atividade de $10.800 \mathrm{unid} / \mathrm{mg}$ de proteína), a pepsina (atividade de 3.600 unid./mg de proteína), a protease tipo XXIII do Aspergillus oryzae (atividade de aproximadamente 4 unid./mg de sólido), o fenol cristalino, o ácido clorídrico e a 
trietanolamina (grau HPLC) foram adquiridos da SigmaAldrich (St. Louis, MO, EUA). A papaína (atividade de 10 unid./mg de proteína) foi gentilmente doada pela BIOBRÁS (Montes Claros, Brasil). O leite em pó desnatado da marca Glória (Itaperuna, RJ, Brasil), sem a adição de vitaminas e sais minerais, foi comprado em um supermercado de Belo Horizonte. A água, usada no cromatógrafo, foi purificada em Sistema de Purificação de Água Aries (Vaponics, EUA). As membranas de celulose, utilizadas para filtração das amostras $(0,20 \mathrm{~mm})$ e dos solventes $(0,45 \mathrm{~mm})$, foram adquiridas da Sartorius (Alemanha).

\section{Métodos}

Preparação dos hidrolisados de leite em pó desnatado Foram preparados sete hidrolisados protéicos a partir de soluções de leite em pó desnatado a $0,35 \%(\mathrm{p} / \mathrm{v})$, correspondendo à concentração protéica de $0,125 \mathrm{~g} / 100$ $\mathrm{mL}$. O tampão $\mathrm{HCl}-\mathrm{KCl} 0,01 \mathrm{~mol} / \mathrm{L}(\mathrm{pH} 1,9)$ foi utilizado na hidrólise pela pepsina (H3). Nas demais hidrólises, utilizou-se o tampão fosfato $0,01 \mathrm{~mol} / \mathrm{L}(\mathrm{pH} 6,0)$. Todas as amostras foram, inicialmente, aquecidas a $80^{\circ} \mathrm{C}$ por 10 min. A seguir, a temperatura foi reduzida para $50^{\circ} \mathrm{C}$, em banho de gelo, e as enzimas, uma protease do Aspergillus oryzae (AO), papaína (PA) e pepsina (PE), foram adicionadas em quantidades suficientes para se obter as relações enzima:substrato desejadas. A AO foi, também, utilizada em associação com a PA e a PE (Tabela I). As reações foram interrompidas abaixando-se a temperatura para $10{ }^{\circ} \mathrm{C}$, em banho de gelo e acetona Imediatamente, após a hidrólise, os hidrolisados foram congelados e liofilizados. O tempo total de hidrólise foi de $5 \mathrm{~h}$, para todas as amostras. As outras condições de reação estão apresentadas na Tabela I.

\section{Fracionamento dos hidrolisados de leite em pó} desnatado

O fracionamento dos hidrolisados foi realizado por cromatografia SE-HPLC em coluna PHEA, como descrito por Silvestre et al. (1994a). As amostras foram dissolvidas na concentração de $0,40 \mathrm{~g} \%(\mathrm{p} / \mathrm{v})$, em solução de ácido fórmico $0,05 \mathrm{~mol} / \mathrm{L}(\mathrm{pH} 2,5)$, e cromatografadas à temperatura ambiente, sob condições isocráticas, a um fluxo de $0,5 \mathrm{~mL} / \mathrm{min}$, durante $35 \mathrm{~min}$. A fase móvel foi filtrada, através de membrana de $0,45 \mathrm{~mm}$, e desgaseificada imediatamente antes do uso. A detecção dos picos cromatográficos foi efetuada em três comprimentos de onda: 230, 280 e $300 \mathrm{~nm}$. As amostras foram analisadas em triplicata e as frações foram separadas, de acordo com o tempo de retenção, sendo F1 de 13,5 a 18,0 min.; F2 de 18,0 a 21,5 min.; F3 de 21,5 a 22,5 min. e F4 de 22,5 a 33,0 $\min$.

\section{Quantificação de peptídeos e aminoácidos livres nos} hidrolisados de leite em pó desnatado

O método rápido da Área Corrigida da Fração (ACF), desenvolvido por Silvestre et al. (1994b), foi utilizado para quantificar os peptídeos e aminoácidos livres presentes nos hidrolisados de leite em pó desnatado. As amostras foram fracionadas e os teores de peptídeos e aminoácidos livres das frações foram calculados, por extrapolação gráfica em uma curva padrão preparada como descrito por Lopes et al. (2003), empregando-se o leite em pó desnatado como substrato. Resumidamente, foram preparados cinco hidrolisados padrões (dois com tripsina e três com pancreatina), que foram fracionados por cromatografia SE-HPLC em coluna PHEA. As quatro frações obtidas foram coletadas, sendo o solvente removido, de cada fração, em evaporador Centrivap, modelo 78100-00D, Labconco (Kansas City, MI, EUA). Em seguida, foram

TABELA I - Condições hidrolíticas empregadas na preparação dos hidrolisados de leite em pó desnatado

\begin{tabular}{ccccc}
\hline Hidrolisados & Tempo de hidrólise (h) & \multicolumn{3}{c}{ E:S (\%) } \\
\cline { 3 - 5 } & & AO & PA & PE \\
\hline H1 & AO (5) & 1 & - & - \\
H2 & PA (5) & - & 1 & - \\
H3 & PE (5) & 1 & - & 1 \\
H4 & AO (1) + PA (4) & 10 & 2 & - \\
H5 & AO (1) + PA (4) & 1 & - & - \\
H6 & AO (1) + PE (4) & 10 & - & 2 \\
H7 & AO (1) + PE (4) & & - \\
\hline
\end{tabular}

$\mathrm{E}: \mathrm{S}=$ Relação enzima:substrato; $\mathrm{AO}=$ protease do Aspergillus oryzae, $\mathrm{PA}=$ Papaína, $\mathrm{PE}=\mathrm{Pepsina}$. Temperatura: $50^{\circ} \mathrm{C}$ 
submetidas à análise de aminoácidos. O cálculo da ACF foi realizado como descrito por Silvestre et al. (1994b). Traçou-se, então, a curva padrão, locando-se a ACF em função do teor de aminoácidos.

\section{Análise Estatística}

Todas as determinações analíticas foram realizadas em triplicatas. Para as determinações das diferenças entre as médias e dos conteúdos de aminoácidos nas frações cromatográficas foram utilizadas a Análise Fatorial $7 \mathrm{x} 4$ (hidrolisados x frações cromatográficas) e o Teste de Duncan. Na determinação da diferença entre as médias das áreas dos picos da Phe nos hidrolisados foram realizadas a Análise de Variância (ANOVA fator único) e o teste de Duncan. A curva padrão foi calculada por regressão linear, empregando dezessete níveis de conteúdo de aminoácidos em nmoles \% com três repetições (PimentelGomes, 2000).

\section{RESULTADOS E DISCUSSÃO}

\section{Caracterização dos hidrolisados de leite em pó desnatado}

\section{Fracionamento por SE-HPLC}

O perfil cromatográfico do hidrolisado $\mathrm{H} 4$, a $230 \mathrm{~nm}$, está apresentado na Figura 1, em que podem ser observadas as quatro frações (F1 a F4) e os picos correspondentes à tirosina (y) e ao triptofano (w), livres.
Diferentes técnicas têm sido empregadas no fracionamento de peptídeos de hidrolisados protéicos. A maioria refere-se ao fracionamento de peptídeos com massa molecular superior a $1000 \mathrm{Da}$. Dentre estas técnicas, destacam-se a eletroforese em gel de poliacrilamida na presença de dodecil sulfato de sódio (SDS-PAGE), a cromatografia de exclusão molecular (SEC), HPLC capilar e de troca de ligante (Lemieux, Amiot, 1989; Adachi et. al. 1991; Armstead, Ling, 1991; Aubry et. al. 1992; Davis, Lee, 1992; Visser et al., 1992; Zhang et al., 1992; Gallagher et al., 1994; Parrado et al., 1993; Perea et al., 1993). Entretanto, estas técnicas têm apresentado série de inconvenientes, tais como, interações secundárias (eletrostáticas ou hidrofóbicas) entre os solutos e a fase estacionária e a ineficiência para separar pequenos peptídeos (Verneuil et al., 1990; Lemieux et al., 1991; Golovchenko et al., 1992). Outros autores, como Lemieux, Amiot (1989) e Davis, Lee (1992), respectivamente, relataram a dificuldade de separar os peptídeos de acordo com o tamanho da cadeia, tendo observado superposição de pesos moleculares, utilizando a SE-HPLC ou a HPLC capilar.

A técnica de SE-HPLC, utilizada no presente trabalho, mostrou ser eficiente na caracterização de hidrolisados protéicos, especialmente quando o interesse está voltado para o fracionamento de peptídeos de baixas massas moleculares, ou seja, inferiores a $1000 \mathrm{Da}$ (Silvestre et al., 1994a; Léonil et al., 2000; Morato et al. 2000, Carreira et al., 2001; Barbosa et al., 2002).

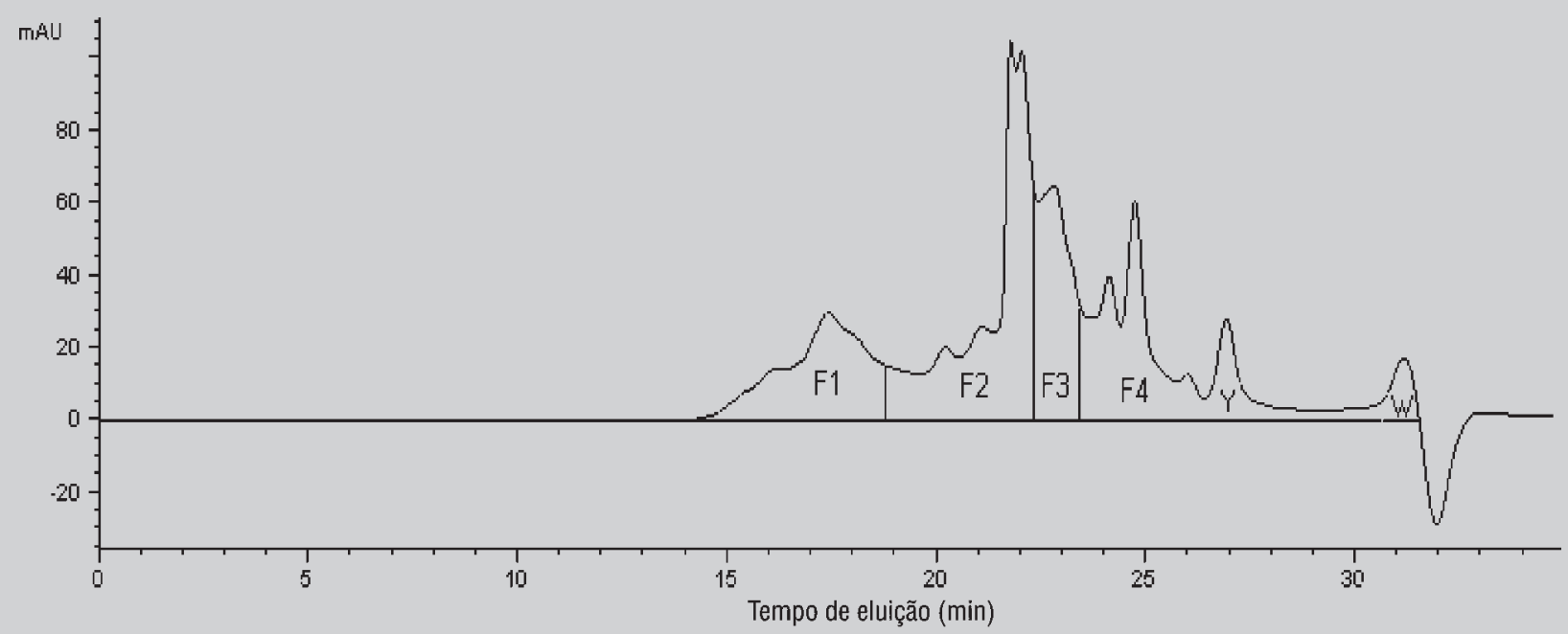

FIGURA 1 - Perfil cromatográfico do hidrolisado H4. Condições: Coluna PHEA ( 250 x 9,4 mn, 5 um e $200 \AA$ - PolylC) $1 \mathrm{~h}$ de hidrólise com a protease do Aspergillus oryzae (relação E:S $=1 \%$ ) mais $4 \mathrm{~h}$ de hidrólise com a papaína (relação $\mathrm{E}: \mathrm{S}=2 \%)$ em tampão fosfato de sódio, $\mathrm{pH} 6,0$ a $50{ }^{\circ} \mathrm{C}$. Detecção das frações a $230 \mathrm{~nm}$. F1: peptídeos grandes $(>7$ resíduos de aminoácidos); F2: peptídeos médios (4 a 7 resíduos de aminoácidos); F3: di- e tripeptídeos; F4: aminoácidos livres. $\mathrm{Y}=$ pico da tirosina, $\mathrm{W}=$ pico do triptofano. 


\section{Quantificação de peptídeos e aminoácidos livres dos hidrolisados}

Os teores de peptídeos e aminoácidos livres nas frações cromatográficas dos hidrolisados estão apresentados na Tabela II. Observa-se uma semelhança, do ponto de vista nutricional, nos perfis peptídicos dos hidrolisados $\mathrm{H} 1$, $\mathrm{H} 2$ e H4, com ligeira superioridade nutricional para o hidrolisado H2, que apresentou o menor teor de aminoácidos livres. Assim, fica evidenciada a vantagem, embora pequena, da ação isolada da enzima papaína (H2), em relação à sua associação com a protease do Aspergillus oryzae (H4). Ressalta-se, ainda que, neste caso, a utilização de apenas uma enzima implica menor custo, principalmente na produção em larga escala.

Considerando-se os diversos fatores citados por González-Tello et al. (1994), que devem ser avaliados em um hidrolisado protéico para uso em dietas especiais, podese concluir que os melhores resultados foram obtidos para os hidrolisados H1, H2 e H4, uma vez que eles apresentaram maiores teores de di- e tripeptídeos (média de 12\%) e peptídeos com massa molecular média de $500 \mathrm{Da}$ (média de $42 \%$ ) e, além disso, baixas porcentagens de aminoácidos livres (média de 19\%).

Os dados da Tabela II indicam, ainda, que o hidrolisado $\mathrm{H} 5$ apresentou os menores teores de grandes peptídeos (F1); no entanto, ele contém uma quantidade de aminoácidos livres bem mais elevada que os demais hidrolisados. Além disso, o H5 foi o hidrolisado mais pobre em peptídeos médios (F2). Por isso, este hidrolisado pode ser considerado o que apresenta o perfil peptídico mais desvantajoso, do ponto de vista nutricional. Entretanto, considerando que o teor elevado de aminoácidos livres poderia levar a maior remoção de Phe, esta preparação deve, também, ser testada quanto ao desenvolvimento de formulações dietéticas para fenilcetonúricos.

\section{Comparação entre os diferentes tratamentos enzimáticos}

Não foram encontrados dados na literatura, abordando os perfis peptídicos obtidos pela hidrólise enzimática do leite em pó desnatado. Este alimento é constituído de mistura de vários nutrientes, sendo que cerca de $85 \%$ das proteínas é representado pela caseína. Portanto, a seguir serão feitas comparações com trabalhos que utilizaram a caseína na caracterização do perfil peptídico.

\section{Ação isolada das enzimas}

Avaliando-se a influência da ação de AO, PA e PE sobre o perfil peptídico de hidrolisados de leite em pó desnatado, pode-se observar na Tabela II que a PA (H2) produziu o melhor perfil peptídico, do ponto de vista nutricional. Assim, comparando-se com a AO (H1), o hidrolisado obtido pela ação de PA apresentou menores teores de aminoácidos livres (12\% e 26\%, respectivamente) e maiores teores de peptídeos médios e de di- e tripeptídeos (F2 + F3), 56\% e 49\%, respectivamente. Na comparação com a PE (H3), verificou-se que a ação da PA levou a menor teor de peptídeos grandes (32\% e 57\%, respectivamente) e maiores teores de médios e de di- e tripeptídeos (F2 + F3), 56\% e 25\%, respectivamente.

Em outros três trabalhos realizados, anteriormente no mesmo laboratório envolvido no presente estudo, a ação isolada de enzimas, sobre o perfil peptídico de hidrolisados protéicos, foi igualmente testada.

TABELA II - Teores de peptídeos e de aminoácidos livres das frações cromatográficas dos hidrolisados

\begin{tabular}{ccccc}
\hline Hidrolisados & \multicolumn{5}{c}{ FRAÇ ÕES } \\
\cline { 2 - 5 } & F1 & F2 & F3 & F4 \\
\hline H1 & $25,55^{2 / \mathrm{c}}$ & $37,80^{1 / \mathrm{b}}$ & $10,92^{3 / \mathrm{a}, \mathrm{b}}$ & $25,74^{2 / \mathrm{d}}$ \\
H2 & $31,98^{2 / \mathrm{b}}$ & $45,3^{1 / \mathrm{a}}$ & $10,59^{3 / \mathrm{a}, \mathrm{b}}$ & $12,13^{3 / \mathrm{f}}$ \\
H3 & $56,86^{1 / \mathrm{a}}$ & $21,09^{2 / \mathrm{c}, \mathrm{d}}$ & $4,14^{3 / \mathrm{c}}$ & $17,92^{2 \mathrm{e}, \mathrm{f}}$ \\
H4 & $26,29^{2 / \mathrm{b}, \mathrm{c}}$ & $41,72^{1 / \mathrm{a}, \mathrm{b}}$ & $13,08^{4 / \mathrm{a}}$ & $18,92^{3 / \mathrm{e}}$ \\
H5 & $6,18^{3 / \mathrm{d}}$ & $18,74^{2 / \mathrm{d}}$ & $6,35^{3 / \mathrm{b}, \mathrm{c}}$ & $68^{1 / 7}, 3^{1 / \mathrm{a}}$ \\
H6 & $30,05^{2 / \mathrm{b}}$ & $25,37^{2 / \mathrm{c}}$ & $8,71^{3 / \mathrm{a}, \mathrm{b}, \mathrm{c}}$ & $35,88^{1 / \mathrm{c}}$ \\
H7 & $20,44^{2 / \mathrm{c}}$ & $24,66^{2 / \mathrm{c}}$ & $8,86^{3 / \mathrm{a}, \mathrm{b}, \mathrm{c}}$ & $46,05^{1 / \mathrm{b}}$ \\
\hline
\end{tabular}

Todos os valores são apresentados em \% nmoles das quatro frações. Os resultados representam a média das triplicatas. Médias indicadas por números iguais não diferem entre si a 5\% de probabilidade na comparação de diferentes frações de um mesmo hidrolisado. Médias indicadas por letras iguais não diferem entre si a 5\% de probabilidade na comparação de uma mesma fração para diferentes hidrolisados. F1: grandes peptídeos (> 7 resíduos de aminoácidos); F2: médios peptídeos (4 a 7 aminoácidos); F3: di- e tripeptídeos; F4: aminoácidos livres. 
Inicialmente, a subtilisina $\left(\mathrm{E}: \mathrm{S}=4 \%, \mathrm{pH} 7,5\right.$ e $\left.40^{\circ} \mathrm{C}\right)$ foi empregada para hidrolisar a caseína, tendo produzido melhor perfil peptídico, especialmente quanto aos teores de di- e tripeptídeos (36\%) e de aminoácidos livres (4\%), quando comparado aos obtidos no presente trabalho (Morato et al., 2000).

Em seguida, a pepsina foi a enzima escolhida por Carreira et al. (2002) para hidrolisar a caseína ( $\mathrm{E}: \mathrm{S}=4 \%$, $\mathrm{pH} 1,9$ e $40{ }^{\circ} \mathrm{C}$ ), produzindo um hidrolisado cujo perfil peptídico se assemelha ao do $\mathrm{H} 3$, com a vantagem de terem obtido menores teores de aminoácidos livres (7\%) do que aqueles descritos neste trabalho (12\%).

Finalmente, o emprego da papaína (E:S=2\%, $\mathrm{pH} 7,5$ e $37^{\circ} \mathrm{C}$ ) foi testado na hidrólise da caseína, tendo obtido melhor perfil peptídico que o do presente trabalho (Morais et al., 2002).

É importante ressaltar que, nos três trabalhos descritos, nos quais se obteve melhor perfil peptídico, quando comparado com o do presente estudo, foram utilizadas condições hidrolíticas diferentes.

\section{Associação das enzimas}

\section{- Efeito da relação E:S}

Neste caso, podem ser avaliados dois tipos de associação, nas quais a relação E:S foi alterada, ou seja, AO com PA e AO com PE.

\section{- Associação de AO com PA}

Observa-se na Tabela II que o aumento de dez vezes na relação E:S (H5 em relação a H4) levou a alterações significativas nos conteúdos das frações cromatográficas, produzindo perfil peptídico de qualidade nutricional inferior. Houve mais de $50 \%$ de redução nos teores de médios (F2) e de di- e tripeptídeos (F3), assim como um aumento de, aproximadamente, quatro vezes no teor de aminoácidos livres (F4). A única alteração vantajosa, do ponto de vista nutricional, refere-se ao decréscimo no conteúdo de peptídeos grandes (F1).

Estes resultados indicam que a elevação da relação E:S, provavelmente, produziu quantidade pequena de di- e tripeptídeos, contendo fenilalanina como segundo aminoácido a partir da porção carboxi-terminal, os quais, de acordo com Liener (1974) e Reed (1975), não serviriam de substratos para a ação da papaína. Isto explicaria, pelo menos em parte, o elevado teor de aminoácidos livres, apresentado pelo hidrolisado H5. Esta modificação na relação E:S não produziu, em termos nutricionais, o resultado desejado e seria inadequado, do ponto de vista econômico, devido ao custo elevado das enzimas, se for considerada a produção em larga escala.

\section{- Associação de AO com PE}

Avaliando-se os efeitos do aumento de dez vezes na relação E:S para a associação de $\mathrm{AO}$ e $\mathrm{PE}$, sobre os perfis peptídicos dos hidrolisados de leite em pó desnatado $(\mathrm{H} 7$ em relação a H6), observa-se que este procedimento não foi prejudicial ao perfil peptídico, como foi observado para aumentos semelhantes na associação de AO com PA (Tabela II). Assim, se por um lado este aumento contribui para elevar o teor de aminoácidos livres (F4), por outro, produziu queda na quantidade de peptídeos grandes (F1). Os teores de peptídeos médios (F2) e di- e tripeptídeos (F3) não sofreram quaisquer alterações. Conclui-se, portanto, que, do ponto de vista nutricional, o perfil peptídico dos hidrolisados H6 e H7 são semelhantes.

Outros trabalhos também relataram o efeito do aumento da relação E:S sobre os teores de peptídeos de hidrolisados protéicos sendo que, em alguns casos, os resultados foram benéficos e, em outros, prejudiciais para o perfil peptídico. Assim, Loosen et al. (1991) testaram a utilização da subtilisina na hidrólise da caseína, variandose a relação E:S de 1 para 4\%, obtendo os melhores resultados empregando-se a relação E:S de $2 \%$, que levou à obtenção de um hidrolisado contendo elevados teores de di- e tripeptídeos e apenas 5\% de aminoácidos livres.

Morato et al. (2000) estudaram a ação da subtilisina associada à tripsina, sobre a hidrólise da caseína. Ao aumentar a relação E:S das enzimas de $2 \%$ para $4 \%$ para a subtilisina e de $10 \%$ para $20 \%$ para a tripsina, estes autores obtiveram alteração desvantajosa sobre o perfil peptídico dos hidrolisados, uma vez que houve decréscimo de di- e tripeptídeos, enquanto que as outras frações mantiveram-se constantes.

Todos estes estudos contradizem a afirmação de González-Tello et al. (1994) de que alteração na relação $\mathrm{E}: \mathrm{S}$ não exerce qualquer influência na distribuição de peptídeos nas frações cromatográficas de hidrolisados protéicos.

- Efeito da segunda enzima adicionada

Neste caso, duas comparações podem ser feitas, H4 com H6 e H5 com H7 (Tabela II) para considerar as mesmas relações E:S, variando-se, apenas, a segunda enzima adicionada (PA ou PE).

- Associação de AO com PA ou PE, para uma relação $E: S$ de $1 \%$ e $2 \%$, respectivamente

A introdução de PA como segunda enzima (H4) foi mais vantajosa (Tabela II), do ponto de vista nutricional, do que a de PE (H6), uma vez que se obteve maior teor de peptídeos médios (F2) e menor teor de aminoácidos livres (F4). Não houve diferenças significativas entre estes dois 
tratamentos, com relação aos teores de grandes peptídeos (F1) e de di- e tripeptídeos (F3).

- Associação de AO com PA ou PE, para relações E:S de $10 \%$ e $20 \%$, respectivamente

Os dados apresentados na Tabela II, indicam que quando se aumentou em dez vezes a relação E:S para as duas enzimas (H7 em relação a H5), foram obtidos resultados nutricionalmente semelhantes para as duas associações.

Inicialmente, observa-se que não houve diferença significativa entre as duas associações, com relação ao teor de di- e tripeptídeos (F3). Ainda, se por um lado, a introdução de PA como segunda enzima (H5) levou à produção de quantidade bem inferior de grandes peptídeos (F1), a utilização de PE, como segunda enzima, deu origem a um hidrolisado (H7) com menor teor de aminoácidos livres (F4). Entretanto, pode-se ressaltar que houve ligeira vantagem de $\mathrm{H} 7$ sobre $\mathrm{H} 5$, no que se refere ao seu teor mais elevado em peptídeos médios (F2).

\section{Ação isolada versus associação de enzimas}

\section{- $\mathrm{AO}$ e $\mathrm{AO}$ com PA}

Comparando-se a ação isolada de $\mathrm{AO}(\mathrm{H} 1)$ e a da sua melhor associação com PA (H4), observa-se na Tabela II, que H4 se apresentou ligeiramente melhor em relação a H1, uma vez que deu origem a teor menor de aminoácidos livres (F4).

A vantagem da associação de enzimas foi, igualmente, relatada por Chataud et al. (1988), que mostraram a superioridade da associação da tripsina com duas enzimas de origem bacteriana, sobre a sua ação isolada, tendo produzido um teor mais elevado de di- e tripeptídeos.

\section{- $\mathrm{AO}$ e $\mathrm{AO}$ com PE}

Comparando-se a ação isolada de $\mathrm{AO}(\mathrm{H} 1)$ e as suas duas associações com a PE (H6 e H7) na Tabela II, observa-se que, ao contrário do que foi relatado para a associação de AO com PA, a ação isolada da enzima (AO) foi mais vantajosa, do ponto de vista nutricional, do que a sua associação com PE tendo produzido um hidrolisado com maior teor de peptídeos médios (F2) e menor teor de aminoácidos livres (F4).

\section{- PA e AO com PA}

Como mostrado na Tabela II, a ação isolada de PA (H2) apresentou ligeira vantagem em relação à sua associação com AO (H4), uma vez que em H2 observa-se menor teor de aminoácidos livres (F4).

Morato et al. (2000), comparando as ações da subtilisina isolada e associada à tripsina na preparação de hidrolisados de caseína, obtiveram também, resultados semelhantes aos do presente trabalho. Estes autores mostraram a superioridade do hidrolisado preparado com a subtilisina, isoladamente, que apresentou maiores teores de di- e tripeptídeos (F3) do que o hidrolisado preparado com a associação das duas proteases.

\section{- PE e AO com PE}

Comparando-se a ação isolada da enzima PE (H3) com as ações de suas duas associações (H6 e H7), observa-se (Tabela II) que a ação isolada de PE e a sua associação com $\mathrm{AO}$ produziram perfis peptídicos semelhantes, do ponto de vista nutricional. Se por um lado $\mathrm{H} 3$ possui maior teor de grandes peptídeos (F1), por outro lado apresentou menor teor de aminoácidos livres (F4).

Entretanto, Carreira et al. (2001b) obtiveram, do ponto de vista nutricional, melhores perfis peptídicos de hidrolisados de caseína, quando associaram a pepsina com a tripsina, em relação aos teores de di- e tripeptídeos.

\section{CONCLUSÃO}

Comparando-se todas as preparações enzimáticas, pode-se concluir que as ações isoladas de $\mathrm{AO}$ e de PA, bem como a associação de AO com PA (E:S de 1\% e 2\%, respectivamente), deram origem a perfis peptídicos semelhantes do ponto de vista nutricional.

No caso da associação de AO com PA, este procedimento foi desvantajoso para o perfil peptídico, enquanto que na associação de $\mathrm{AO}$ com $\mathrm{PE}$ não produziu alteração significativa.

O efeito da adição da segunda enzima na associação enzimática de $\mathrm{AO}$ com PA ou com PE mostrou ser dependente da relação E:S empregada. Para uma relação E:S de $1 \%$ e $2 \%$ (primeira e segunda enzimas, respectivamente), a ação da PA foi mais vantajosa que a da PE para o perfil peptídico, enquanto que o inverso foi obtido para uma relação E:S de $10 \%$ e $20 \%$ (primeira e segunda enzimas), respectivamente.

O estudo comparativo das ações isoladas das três enzimas (AO, PA e PE) com as suas diversas associações revelou a superioridade, em termos de perfil peptídico, do primeiro procedimento.

\section{AGRADECIMENTOS}

Este trabalho contou com o apoio financeiro das agências CNPq e FAPEMIG, nas formas de auxílio à pesquisa e bolsas de Aperfeiçoamento e Iniciação Científica. 


\section{ABSTRACT \\ Peptide profile of enzymatic hydrolysates from skim milk powder}

Seven enzymatic hydrolysates from skim milk powder were prepared with the aim of producing dietary supplement for phenylketonurics. A protease from Aspergillus oryzae (AO), papain (PA) and pepsin (PE), separately or in association, were used in different enzyme:substract ratios (E:S), at $50{ }^{\circ} \mathrm{C}$ and total reaction time of $5 \mathrm{~h}$. The distribution of peptides according to chain length was used to evaluate the nutritional quality of protein hydrolysates. Initially, the hydrolysates were fractionated by high-performance liquid chromatography in size-exclusion mode (SE$H P L C)$ and the rapid method of Correct Fraction Area (CFA) was used for quantifying the peptides and amino acids in the chromatographic fractions. The results showed the advantage of isolated action of each enzyme when compaired with the associations studied. Among all tested preparations, the isolated action of $A O$ and $P A$, and the association of these two enzymes in E: $S$ ratio of $1 \%$ and $2 \%$, respectively, produced hydrolysates having similar peptide prolifes, with the highest proportion of di-and tripeptides and the lowest of free amino acids.

UNITERMS: Dietary supplement. Peptide profile. Enzymatic hydrolysis. Phenylketonuria. Skim milk powder.

\section{REFERÊNCIAS BIBLIOGRÁFICAS}

ADACHI, S.; KIMURA, Y.; MURAKAMI, K.; MATSUNO, R.; YOKOGOSHI, H. Separation of peptide groups with definite characteristics from enzymatic protein hydrolysate. Agric. Biol. Chem., v.55, n.4, p.925-932, 1991.

ADIBI, S.A.; MORSE, E.L. Intestinal transport of dipeptides in man: relative importance of hydrolysis and intact absorption. J. Clin. Invest., v.50, n. 3, p.2266-2275, 1971.

ADIBI, S. A.; SOLEIMANPOUR, M. R. Functional characterization of dipeptide transport system in human jejunum. J. Clin. Invest., v.53, n. 2, p.1368-1374, 1974.

ARMSTEAD, I. P.; LING, J. R. Chromatographic separation of mixed peptides from amino acids in biological digests with volatile buffers. J. Chromatogr., v.586, n.3, p.259263, 1991.
AUBRY, A. F.; CAUDE, M.; ROSSET, R. Separation and identification of dipeptides in an hydrolyzed brain extract. Chromatogr., v.33, n.3, p.533-538, 1992.

BARBOSA, C. M. S.; MORAIS, H. A.; SILVA, V. D. M.; OLIVEIRA, M. C.; SILVESTRE, M. P. C. Padronização de método analítico para avaliação do grau de exposição de fenilalanina em hidrolisados de caseína, por espectrofotometria derivada segunda. Rev. Bras. Ciên. Farmac., São Paulo, v.38, n.1, p.113-119, 2002.

CÂNDIDO, L.M.B. Obtenção de concentrados e hidrolisados protéicos de tilápia do nilo (Oreochromus niloticus): composição, propriedades nutritivas e funcionais. Campinas, 1998.207 p. [Tese de Doutorado. Faculdade de Engenharia de Alimentos da Universidade Estadual de Campinas].

CARREIRA, R. L.; MORAIS, H. A.; BARBOSA, C. M. S.; MOTTA, S.; SILVESTRE, M. P. C. Otimização na produção de di- e tripeptídeos em hidrolisados de caseína pela associação de enzimas: pepsina, tripsina e subtilisina. Braz. J. Food. Tech., Campinas, v.4, n.5, p.103-108, 2001.

CHATAUD, J.; DESREUMEUX, S.; CARTWRIGHT, T. Procédé de fabrication dun hydrolysat enzymatique de proteins riche en di- et tri-peptides, utilizable notamment en nutrition artificielle et en dietétique. Laboratório Roger Bellon, Neuilly-sur-Seine-Fr. A23J3/00. FR87402837.6, 0.274946A1. 14/12/1987, 20/07/1988.

CLEMENTE, A. Enzimatic protein hydrolysates in human nutrition. Trends Food Sci. Technol., v.11, n. 7, p.254262,2000 .

DAVIS, M.; LEE, T.D. Analysis of peptide mixtures by capillary high performance liquid chromatography: a practical guide to small-scale separations. Prot. Sci., v.1, n. 2, p.935-944, 1992.

FREITAS, O.; PADOVAN, G. J.; VILELA, L.; SANTOS, J. E.; DUTRA DE OLIVEIRA, J. E.; GREENE, L. J. Characterization of protein hydrolysates prepared for enteral nutrition. J. Agric. Food Chem., v.41, n.8, p.1432$1438,1993$.

FROKJAER, S. Use of hydrolysates for protein supplementation. Food Technol., v.48, n.10, p.86-88, 1994. 
GALLAGHER, J.; KANEKANIAN, A. D.; EVANS, E. P. Hydrolysis of casein: a comparative study of two proteases and their peptide maps. Int. J. Food Sci. Tech., v.29, n.3, p.279-285, 1994.

\section{GOLOVCHENKO, N.; KATAEVA, I. A.; AKIMENKO,} V. K. Analysis of $\mathrm{pH}$-dependent protein interactions with gel filtration medium. J. Chromatogr., v.591, n.4, p.121128, 1992.

GONZÁLEZ-TELLO, P.; CAMACHO, F.; JURADO, E.; PAÉZ, M. P.; GUADIX, E. M. Enzymatic hydrolysis of whey proteins. II. Molecular-weight range, Biotech. Bioeng., v.44, n.4, p.529-532, 1994.

GRIMBLE, G. K.; SILK, D. B. A. Peptides in human nutrition. Nutr. Res. Rev., v.2, n. 1, p.87-108, 1989.

HARA, H.; FUNABIKI, R.; IWATA, M.; YAMAZAKI, K. Portal absorption of small peptides in rats under unrestrained conditions. J. Nutr., v. 114, n.3, p.1122-1129, 1984.

KASAI, T.; SAKAMAKI, T.; KIRIYAMA, S. Modified process for preparation of ozonated casein and nutritional evaluation of the product with rats. Biosci. Biotechnol. Biochem., v.58, n. 3, p 451-454, 1994.

KEOHANE, P. P.; GRIMBLE, G. K.; BROWN, B.; SPILLER, R. C. Influence of protein composition and hydrolysis method on intestinal absorption of protein in man. Gut., v.26, n. 3, p.907-913, 1985.

KITAGAWA, T.; OWADA, M.; AOKI, K.; ARAI, S.; OURA, T.; MATSUDA, I.; IGARASHI, Y.; TADA, K.; KATAYAMA, S.; HASHIDA, W. Treatment of phenylketonuria with a formula consisting of low phenylalanine peptide. Enzyme, v.38, n. 1, p.321-327, 1987.

LEMIEUX, L.; AMIOT, J. Application of reversed-phase high-performance liquid chromatography to separation of peptides from phosphorylated and dephosphorylated casein hydrolysates. J. Chromatogr., v.73, n.1, p.189-206, 1989.

LEMIEUX, L.; PIOT, J. M.; GUILLOCHON, D.; AMIOT, J. Study of the efficiency of a mobile phase used in sizeexclusion HPLC for the separation of peptides from a casein hydrolysate according to their hydrodynamic volume, J. Chromatogr., v.32, n. 2, p.499-504, 1991.
LÉONIL, J.; GAGNAIRE, V.; MOLLÉ, D.; PEZZENEC, S.; BOUHALLAB, S. Application of chromatography and mass spectrometry to the characterization of food proteins and derived peptides. J. Chromatogr. A, v.881, n. 1/2,p.1-21, 2000 .

LIENER, I. E. The sulfhydryl proteases. In: WHITAKER, J. R. Food related enzymes. Washington: American Chemistry Society, 1974. 374p. (Advances in Chemistry Series, 136).

LOOSEN, P. C.; BRESSPOLLIER, P. R.; JULIEEN, A. R.; PEJOAN, C. H; VERNEUIL, B. Procede pour preparer um hydrolysat enzymatique. Tessenderlo Cheemie n. v. [BE/BE]; Stationsstraat, B-3980 Tessenderlo (BE). A23J3/34, C12P21/06 C12S3/14, C07K15/00//A61K37/18, A23J3/04, 3/14. FR-PCT/ BE91/00001, W091/10369. 11/01/1991; 25/07/1991. (Verificar).

LOPES, D. C. F.; SILVA, V. D. M.; MORAIS, H. A.; SANTORO, M. M.; FIGUEIREDO, A. F. S.; SILVESTRE, M. P. C. Hidrolisados enzimáticos de leite em pó desnatado como fonte de oligopeptídeos para formulações dietéticas. Nutrire, 2003 (no prelo).

LOPEZ-BAJONERO, L. J.; LARA-CALDERON, P.; GALVEZ-MARISCAL, A.; VELASQUEZARELLANO, A .; LOPEZ-MUNGUIA, A. Enzimatic production of a low-phenilalanine product from skim milk powder and caseinate. J. Food Sci., v.56, n.4, p. 938-942, 1991.

MAHAN, L. K.; STUMP, S. E. Krause - Alimentos, nutrição e dietoterapia. 9. ed. São Paulo: Editora Rocca, 1998. $1179 \mathrm{p}$.

MIRA, N. V. M.; MARQUEZ, U. M. L. Importância do diagnóstico e tratamento da fenilcetonúria. Rev. Saúde Pública, v. 34, n.1, p.86-96, 2000.

MORAIS, H. A.; BARBOSA, C. M. S.; LOPES, D. C. F.; OLIVEIRA, M. C.; Silvestre, M. P. C. Caracterização do perfil peptídico e de aminoácidos em hidrolisados de caseína. Arch. Lat. Am. Nut., v.52, n.1, p.77-83, 2002.

MORATO, A. F.; CARREIRA, R. L.; JUNQUEIRA, R. G.; SILVESTRE, M. P. C. Optimization of casein hydrolysis for obtaining high contents of small peptides: use of subtilisin and trypsin. J. Food Compos. Anal., v.13, n.5, p.843-857, 2000 . 
MOSZCZYNSKI, P.; IDZIAC, J. Preparation of enzymatic hidrolysates of casein depleted in phenyllalanine. Appl. Biochem. Microbiol., v. 29, n. 3, p. 302-306, 1993.

NUPAD. Comunicação pessoal, Belo Horizonte, 2002.

OUTINEN, M. T.; TOSSAVAINEN, O.; HARJU, M.; LINKO, P. Method for removing phenilalanine from proteinaceous compositions, a product so obtained and use thereof. Valio Oy, Helsink, Finland, Patents US 5547687, A23J3/34B4; A23J3/34C; A23L1/015E2; A61K38/01B; A61K38/01D6. 12/09/1994; 20/08/ 1996. (verificar)

PARRADO, J.; MILLAN, F.; HERNANDEZ-PINZÓN; BAUTISTA, J.; MACHADO, A. Characterization of enzymatic sunflower protein hydrolysates. J.Agric. Food Chem., v.41, n.11, p.1821-1825, 1993.

PEREA, A.; UGALDE, U.; RODRIGUEZ, I.; SERRA, J. L. Preparation and characterization of whey protein hydrolysates: applications in industrial whey bioconversion processes. Enz. Microb. Technol., v.15, n.11, p.418-423, 1993.

PIMENTEL-GOMES, F. Curso de estatística experimental. 14. ed. Piracicaba: ESALQ, 2000. 477p.

REED, G. Enzymes in food processing. 2. ed. New York: Academic Press, 1975. 573p.

SHIMAMURA, S.; TAMURA, Y.; MIYAKAWA, H.; SAITO, H.; KAWAGUCHI, Y.; ISOMURA,N.; AKAZOME, Y.; OCHI, H.; KAWAMOTO, M. Peptide mixture and products thereof. Morinaga Milk Industry Co., Ltd., Tokio, Japan, Patents US 5952193, A23C 21/02; A23C 21/04; A23C 21/06; A61K 38/01. 14/04/ 1997; 14/09/1999.(Verificar).
SILVESTRE, M. P. C.; HAMON, M.; YVON, M. Analysis of protein hydrolysates. 1. Use of poly (2-hydroxyethylaspartamide)-silica column in size-exclusion chromatography for the fracionation of casein hydrolysates. J. Agric. Food Chem., v.42, n.12, p.27782782, 1994a.

SILVESTRE, M. P. C.; HAMON, M.; YVON, M. Analyses of protein hydrolysates. 2. Characterization of casein hydrolysates by a rapid peptide quantification method. $J$. Agric. Food Chem., v.42, n.12, p.2783-2789, 1994b.

SMITHERS, G. W.; BRADFORD, R. S. New casein products: fresh opportunities for the dairy industry. Food Res. Quart., v.51, n.1, p.92-98, 1991.

TAKASE, M.; KAWASE, K.; DIYOSOWA, I.; OGASA, K.; SUSUKI, S.; KUROUME, T. Antigenicity of casein enzymatic hydrolysate. J. Dairy Sci., v.62, n.11, p.15701576, 1979.

VERNEUIL, B.; BRESSOLIER, P. H.; JULIEN, R. Quantification of amino acids, and di- and tripeptides in nutritional interest protein hydrolysates by ligand exchange chromatography in combination with Edman degradation. SYMPOSIUM ON PURIFICATION TECHNOLOGIES, 4., 1990. Resumos. Clermont-Ferrand: s.c.p., 1990. p.253-258.

VISSER, S.; SLAGEN, C. J.; ROBBEN, A. J. P. M. Determination of molecular mass distributions of whey protein hydrolysates by high-performance size-exclusion chromatography. J. Chromatogr., v.599, n.2, p.205-209, 1992.

ZHANG, Y.; DORJPALAM, B.; HO, C. T. Contribution of peptides to volatile formation in the Maillard reaction of casein hydrolysate with glucose. J. Agric. Food Chem., v.40, n. 5, p.2467-2471, 1992.

Recebido para publicação em 07 de abril de 2003. Aceito para publicação em 20 de agosto de 2004. 